\title{
Sylvaine Guinle-Lorinet, Libérer le prêtre de l'État clérical. Échanges et dialogue (1968-1975)
}

Paris, L'Harmattan, coll. « Le monde en transition », 2008, 298 p.

\section{Frédéric Gugelot}

\section{(2) OpenEdition}

\section{Journals}

Édition électronique

URL : http://journals.openedition.org/assr/25499

DOI : $10.4000 /$ assr.25499

ISSN : $1777-5825$

\section{Éditeur}

Éditions de l'EHESS

Édition imprimée

Date de publication : 30 décembre 2013

Pagination : 208

ISSN : 0335-5985

Référence électronique

Frédéric Gugelot, « Sylvaine Guinle-Lorinet, Libérer le prêtre de l'État clérical. Échanges et dialogue (1968-1975) », Archives de sciences sociales des religions [En ligne], 164 | 2013, mis en ligne le 03 mars 2014, consulté le 21 septembre 2020. URL : http://journals.openedition.org/assr/25499; DOI : https:// doi.org/10.4000/assr.25499

Ce document a été généré automatiquement le 21 septembre 2020.

(c) Archives de sciences sociales des religions 


\section{Sylvaine Guinle-Lorinet, Libérer le prêtre de l'État clérical. Échanges et dialogue (1968-1975)}

Paris, L'Harmattan, coll. « Le monde en transition », 2008, 298 p.

\section{Frédéric Gugelot}

\section{RÉFÉRENCE}

Sylvaine Guinle-Lorinet, Libérer le prêtre de l'État clérical. Échanges et dialogue

(1968-1975), Paris, L'Harmattan, coll. « Le monde en transition », 2008, 298 p. 
1 L'ouvrage se divise en deux principales parties. La première est une histoire bataille du mouvement, de sa création (le 3 novembre 1968) à sa disparition (16 février 1975). Histoire-débat plutôt tant le mouvement apparaît comme un groupe de pression ou d'interpellation dont la puissance dépasse largement les effectifs. Le mouvement se réclame en effet d'un collectif de mille prêtres à ces débuts, il en compte réellement 609 en janvier 1969, sur environ 40000 prêtres séculiers. Ce mouvement de prêtres, au départ, permet l'expression du malaise de certains clercs sur la nature, la fonction et le rôle du sacerdoce ministériel au moment où la crise des vocations s'amplifie et les départs de prêtres se multiplient (voir Martine Sevegrand, Vers une Église sans prêtres (1945-1978), Presses

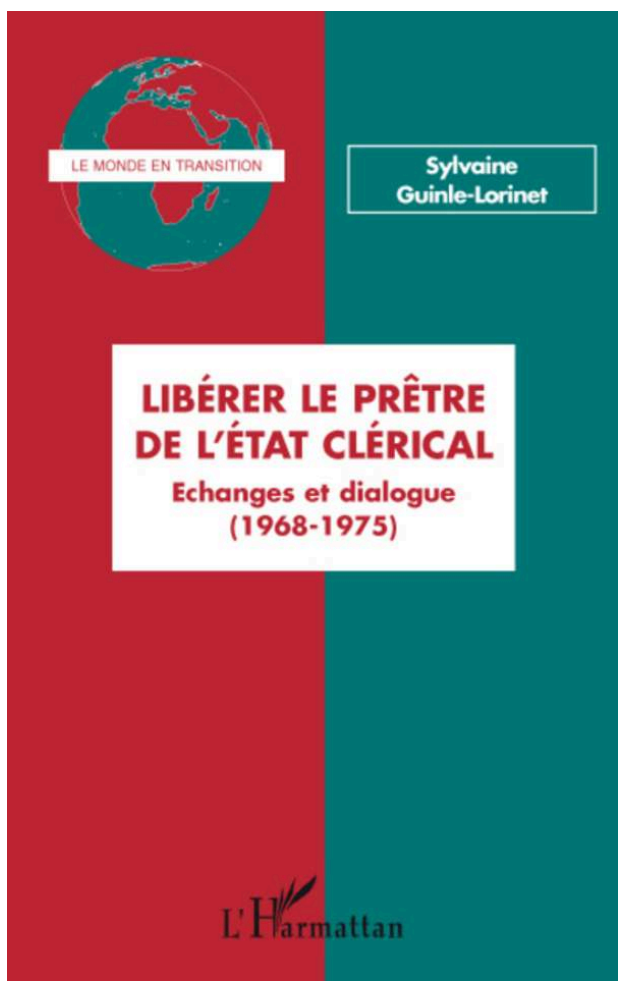
universitaires de Rennes, 2004). Le mouvement veut répondre à cette crise d'identité.

2 L'auteur procède donc à une analyse factuelle et textuelle du mouvement. Échanges et dialogue aspire à obtenir un nouveau statut du clergé qui permettrait à celui-ci de travailler, se marier et militer politiquement et syndicalement. Mais minoritaire, sans relais épiscopal, le mouvement se radicalise. Les aspirations passent progressivement d'une "déclergification » de l'Église à un programme révolutionnaire au sein de l'institution et de la société.

3 Le livre montre que le mouvement est divers et éclaté. L'auteur affirme que les aspirations des jeunes prêtres en voie d'émancipation par le mariage et le travail ne correspondent pas toujours avec celle de prêtres plus anciens " gauchistes » (p. 68) qui mettent l'accent sur les luttes politiques. Le marxisme est pour eux une grille de lecture dont il dégage deux notions qui lui semblent opératoires dans leur combat pour la déclergification : la lutte des classes et l'aliénation.

4 L'auteur insiste sur le fait que le mouvement est une réponse soixante-huitarde à une ancienne question. L'aspiration à la libération qu'exprime le manifeste du 3 novembre 1964 s'inscrit parfaitement dans l'air du temps : « dans la société actuelle où la grande majorité des travailleurs est l'objet d'exploitation [...], cette décision conduit à rejoindre le mouvement pour la libération de tous et de chacun ». Ce qu'Échanges et dialogue promeut d'abord est la fin de la distinction entre Église enseignante et Église enseignée. Il n'apparaît néanmoins pas comme créateur de théologie même s'il défend avec ardeur des théologiens menacés. D’inspiration évangélique, le mouvement s'oriente alors naturellement vers le marxisme. Il passe d'un mouvement de prêtres à une association de chrétiens critiques. Celui-ci démontre une capacité d'activisme tous azimuts impressionnante fondée sur une présence militante, pas si nombreuse (une dizaine de militants, deux ou trois chefs) mais extrêmement engagée. L'auteur insiste 
sur la capacité de mobilisation médiatique d'Échanges et dialogue. Peut-on pour autant parler de «vedettisation » pour évoquer le rôle de Robert Davezies? Le terme est un peu fort. En tout cas, grâce à la tribune offerte par les médias, Davezies popularise les buts du mouvement et offre un visage à un groupe constitué en réseau plus qu'unifié.

5 La seconde partie montre l'échec du mouvement qui ne parvient pas à modifier l'ecclésiologie. Échanges et dialogue développe une vraie critique de l'appareil ecclésial et affirme un idéal révolutionnaire, empreint de tiers-mondisme. Néanmoins, il ne suscite pas un vrai mouvement d'idées au sein de l'institution. Jésus et les Évangiles sont au cœur de leurs engagements, mais ses conceptions apparaissent comme un bricolage fait d'emprunt divers tant chez des théologiens allemands qu'anglo-saxons, patiné de quelques français.

6 Jamais mouvement n'a d'ailleurs aussi mal porté son nom selon l'auteur, inspiré par une utopie révolutionnaire, s'inscrivant dans un prophétisme ardent, il se veut à l'avant-garde de la contestation en faveur d'une Église réformée. Il rêve d'un prêtre serviteur et prophète au sein d'une Église servante et pauvre. Il faut insister sur cet aspect essentiel de nombre de tentatives de réforme $\mathrm{du} \mathrm{xx}^{\mathrm{e}}$ siècle, elles se situent toutes, au départ, dans l'institution qu'il ne s'agit pas de quitter, mais de changer. " Les hommes et les femmes d'Échanges et Dialogue se veulent d'Église» (p. 278). De façon significative, la situation de l'Église réformée ou celle des pasteurs ne sont jamais évoquées malgré la présence de Georges Casalis en son sein. Preuve que l'alternative réformée n'existe pas aux yeux des membres.

7 Le bilan est celui d'un échec collectif selon Sylvaine Guinle-Lorinet. Sans théologie structurée, le mouvement ne parvient pas à fonder son ecclésiologie d'autant qu'il laisse de côté des questions essentielles. Ainsi s'il défend le mariage des prêtres, ni la sexualité ni, et encore moins, l'homosexualité ne sont l'objet d'aucune réflexion, de débat ou de propositions. De même, le groupe ne s'est ainsi jamais interrogé sur la place des femmes en son sein. "Échanges et Dialogue en reste à des conceptions cléricales ou néo-cléricales sur la femme ou sur la sexualité ; il perd une opportunité de poser les vraies questions, à la hiérarchie d'une part, aux laïcs d'autre part » (p. 272).

8 L'ouvrage apparait alors plus comme un seuil de sortie individuel pour des clercs en déshérence. Il y perd une partie de ses forces vives, d'autant que les sortants ne deviennent pas pour autant des soutiens. Ils s'éloignent silencieusement. 